\title{
Seasonal Prevalence of Malaria in Tribal Mandals of Visakhapatnam District, Andhra Pradesh, India
}

\author{
Ponnada Srinivasu \\ Department of Zoology, Andhra University, Visakhapatnam 530 003. A.P. India
}

\begin{abstract}
Malaria is known to the disease of poor people. The tribals living on Visakhapatnam hill tracts of Eastern Ghats are suffering from malaria more seasonally. During the present study Plasmodium falciparum is identified as more dominated than Plasmodium vivax. Apart of the tribal living conditions the ecological conditions of the habitat may also influence to the seasonal prevalence of malaria.
\end{abstract}

Keywords: Malaria, Seasonal, Tribals, Visakhapatnam.

\section{Introduction}

Malaria is considered essentially a disease of the poor countries and, is included under tropical diseases by WHO. In South East Asia, India contributes $60 \%$ of the total incidences of malaria followed by Srilanka (9.7\%) and Thailand (9.2\%) (WHO, 1996). In malaria, endemic zones various factors influence the prevalence of its intensity. Seasonal variations in the incidence of the disease caused by these species have been reported from different parts of the world by iroy and Akkardej (2005) in Tailand; Wasif et al. (2011) in Bangladesh; Enosolease and Awodu (2003) in Nigeria) and have been shown to be significantly associated with high prevalence in the malaria endemic zones (Samuel and Anya, 2004). Further several authors studied the seasonal variation of Malaria, Gyan Chand and Tiwari (2001) on tribals of Sarguja District. Indian; Samdi, Ajayi and Ayanlade (2012) in Paediatric Population of North Eastern Nigeria; Anjali Singh1 and Bhagyalaxmi (2010) in Ahmedabad District, India and Shahid Jamil and Muhammad Nawaz Khan (2009) in Peshawar, Pakisthan.

Malaria is noticed as a major public health problem in tribal area in North East Coastal district of Visakhapatnam of Andhra Pradesh state, India. The Visakhapatnam District topographically bounded by Bay of Bengal in East, the North and West studded with hill tracts of Eastern Ghats and South with East Godavari district. The district has 44 mandals out of which 11 mandals are exclusively inhabited by the tribal communities. There are 22 different tribal communities about 5, 66,893 population $(2,83,191$ male and 2,83,702 female) spread on the hill tracts of the district and living with individual integrity. Malaria is one of the major and continuous health problem noticed among the tribals. The hilly forested environment on one hand and traditional living conditions and agriculture on the other hand people do not have opportunity get access to health and medical care facilities, there by suffering from secured ailments besides seasonal fevers.

The present study is taken up to understand the prevalence of malaria in tribal area with reference to four mandals in Visakhapatnam District. Hence it is important to understand the seasonality of malaria in order to alert to implement proper malaria control measures.

\section{Materials and Methods}

The study has conducted during the period March, 2007 to February, 2008. Randomly 327 villages in four Mandals and 2226 who were suffering from fevers were selected at monthly intervals. Blood samplings were collected from the patients suffering from fever. The blood smear were analysed in the laboratory by applying the Giemsa stain to identify the malaria infection. The particulars of the Data were presented in the results (Table 1).

The data collected is formulated into tables to get inferences related to malaria infection. All these malaria cases are further divided in to two kinds based on the species. The collected data of malaria is pooled together and distributed against the three seasons, and the mean values presented in the results.

\section{Results and Discussion}

The tribal people traditionally lead in a small colonial and composite life style. The majority of the tribals still continue thatched houses for their shelter. Their life style also mingled with the domesticated live stalk and the cattle sheds are also built by attached to their houses (Fig.1).

Lack of proper landscaping due to the hill slops and sanitation specialties, the stagnated water forms small size pools which ultimately habitate to the mosquitoes (Fig. 2).

These tribals usually depend on well or oozing water which the collecting from faraway places. In the hilly region of tribals, the rains continued even in the winter also. The stagnated swamps and pools with water 
and vegetative garbage were found more in the winter season. In peak rainy season all these were disappeared due to the flash out by the heavy rain water. Hence the malaria spread vector survival rate may be very low.

In the present study, two types of malaria infection, Plasmodium vivax and Plasmodium falciparum has been noticed very prominently in tribals. During the study period death cases also noticed (Pedabayalu-21, Paderu -11, Munchingput -7 persons and Hukumpet -3 ) due to the malaria. It indicates the severity of the infection in the study area. The results are presented clearly in Table 2 and Figure $3 \& 4$ reveals the rate of malaria infection is very high in the majority (99\%) of the villages (Fig. $5 \& 6$ ).

Season wise analysis reveals that the Plasmodium falciparum is affected more in winter season than the other seasons (summer and rainy seasons). But in case of Plasomodium vivox there is significant pattern in the intensity of infection and some fluctuations were observed in the results. When compare between the two species Plasmodium falciparum is more dominated than Plasmodium vivox in the all seasons. Plasmodium falciparum is the highest $1.12 \%$ infection is recorded in winter in Hukumpet mandal whereas the lowest $0.18 \%$ in summer in Pedabayalu mandal. In case of Plasmodium vivax, the highest $0.18 \%$ is noticed both in summer and winter in Munchingput mandal and in summer the lowest $0.11 \%$ in Hukumpet and Pedabayalu mandals. In Plasmodium vivax there is no systematic patterns in the prevalence of malaria except some peaks.

It is often believed that the lack of hygienic and sanitation may be the root cause in addition to their innocent and traditional life styles are the major reasons for wide spread of malaria in the Visakhapatnam tribal area.

Anjali Singh and Bhagyalaxmi (2010) observed high rate of infection during the monsoon months from July to October. Pull and Gramiccia (1976), \& Gadzama (1983) reported that the Malaria infection shows seasonal fluctuations with peaks in the wet season and a low level in the dry season. Viroj and Akkarj (2005), \& Enosolease andAwodu, (2003) reported that the malaria infection very high during the rainy season than other seasons. However, detailed studies of the interaction of rainfall increases in malaria transmission in highland areas in Africa where temperature rather than rainfall has been the parameter of greatest interest (Ayanlade et al., 2010).

In the present study, the most dominant species Plasmodium falciparum transmitting malaria is abundant during the winter season and Plasmodium vivax in winter and summer seasons. The peak transmission was observed after the magnitude of rains, number of rainy days and agricultural pattern are the factors, which determine the breeding of vectors, its density and longevity.

Yasinzai and Kakarsulemankhel (2008) stated that the Plasmodium falciparum malaria was common in mid-winter and early spring followed by high prevalence of Vivax malaria in late spring and summer season. This is in contrast with the wet forest areas of Nigeria where malaria transmission occurs at high level all year round (FMOH, 1991). Enosolease and Awodu (2003) have also reported that malaria parasitaemia fluctuates throughout the year without any clear pattern and devoid of seasonality in Benin, Southern Nigeria.

Thomson et al. (2005) and Ayanlade et al. (2010) stated that the seasonality of climate greatly influences the seasonality of malaria transmission. The seasonal variation in any infectious diseases particularly bacterial infections and malaria are shown quarterly variation in a year (Mermel, 2011; Madhavan, 2001).

There are many reasons why certain plasmodium or disease transmission favour specific seasons. Rain fall provides mosquitoes a breeding ground leading to upsurge in the malarial cases during the rainy season (Madhavan, 2001). During the rains large pools are formed which are the preferred breeding sites for vectors (ICMR). The greater extent of potential vector habitats and a high vector density can be the reason for higher prevalence of malaria in such places (Krishnamurthy et al., 2005).

In the present studies also show in the same pattern of prevalence in the malaria. Especially Plasmodium falciparum during the winter and with some fluctuations Plasmodium vivax during the winter and summer recorded more.

\section{References}

[1]. Anjali Singh, A Bhagyalaxmi, (2010). Parasitological observations on seasonality and prevalence of malaria in ahmedabad district through idsp. Indian J. Prev. Soc. Med. Vol. 41 No.3 \& 4.

[2]. Ayanlade, A., Adeoye, N. O., \& Babatimehin, O. (2010). Climate change /variability and malaria transmission in sub-Saharan Africa: A case of Nigeria. Report of the Royal Norwegian Society of sciences and Letters 250pp.

[3]. Enosolease, M. E., \& Awodu, O. A. (2003). Seasonal variation of malaria parasitaemia in an Urban Tropical. City. Nigeria. J. Clin. Pract. 6 (1), 30-33.

[4]. Federal Ministry of Health. (1991). Malaria in Nigeria Epidemiology and control, Nig. Bull. Epid, 1 (3), 1-19.

[5]. Gadzama, N.M. (1983). Mosquito Vectors of the Sahel savanna and environmental development. Annals. Of Borno, 1, 99-104.

[6]. Gyan Chand, R.S.Tiwari, (2001). Parasitological observations on Prevalence, seasonality and transmission of Malaria in among tribals of Sarguja District. Indian Journal of CommunityMedicine.; XXVI (4): 183-88.

[7]. ICMR, A Profile of malaria research center, Bionomics of Malaria Vectors in India, Vector Biology: 19-31.

[8]. K. Krishnamurthy, P.Jambulingam, R.Natarajan, A.N. Sriram, P.K.Das SC Singal, Altered environment and risk of malaria outbreak in South Andaman, Andaman \& Nicobar Island, India affected by tsunami disaster. Malaria journal.2005; 4:32.

[9]. Madhavan KT, Jajoo UN, Bhalia A. (2001). Seasonal variations in incidence of severe and complicated malaria in central India. Indian J Med Sci; 55(1):43-6. 
[10]. Mermel L. MRSA infection shown to be seasonal. (2011). Available from: http://www.sciencedaily.com/releases/ 2011/03/ 110324153502.htm

[11]. Mermel L. MRSA infection shown to be seasonal. [cited on 10th April 2011]. Available from: http://www.sciencedaily.com/

[12]. Oguche, S., Samdi, L. M., Molta, N. B., et al. (2006). A four-year (2001-2004) hospital based retrospective study on morbidity and mortality due to malaria in the Sahel North Eastern Nigeria. J. Mal. Afri .Trop, 2 (2), 56-68.

[13]. Pull, J. H., \& Gramiccia, G. (1976). Research in malaria control in Africa. WHO Chronicle, 30, $286-289$.

[14]. Samdi, L. M., Anyanwu, G. I., Molta, N. B., et al. (2006). Determination of malaria vectorial status of Anopheles mosquitoes of the Sahel, Northeastern Nigeria. J. Life and Envtal Sci., 8 (1 and 2), 442-448.

[15]. Samdi. L. M., Ajayi J. A. and Oguche, S. and Ayanlade, A. (2012). Seasonal Variation of Malaria Parasite Density in Paediatric Population of North Eastern Nigeria Global Journal of Health Science Vol. 4, No. 2.

[16]. Samuel E, Anya. (2004) Seasonal variation in the risk and causes of maternal death in Gambia: Malaria appears to be an important factor. Am J Trop Med Hyg;70:510-3.

[17]. Shahid Jamil, Muhammad Nawaz Khan (2012). Seasonal variations of vivax and falciparum malaria: an observation at a tertiary care hospital. J. Ayub Med Coll Abbottabad;24(1).

[18]. Thomson, M. C., Connor, S. J., Phindela T., et al. (2005). Rainfall and seasurface temperature monitoring for malaria early warning in Botswana. Am J Trop Med Hyg, 73, 214-221.

[19]. Wasif A Khan, David A Sack, Sabeena Ahmed, Chai S Prue, Mohammad Alam, Rashidul Haque, Jacob Khyang, Malathi Ram, Jasmin Akter, Myaing M Nyunt, Douglas Norris, Gregory Glass, Timothy Shields, Md Z Haq, Alejandro Cravioto and David J Sullivan.(2011). Mapping hypoendemic, seasonal malaria in rural Bandarban, Bangladesh: a prospective surveillance. Malaria Journal, 10:124 doi:10.1186/1475-2875-10-124.

[20]. WHO, (1996) Weekly Epidemiological Report No.3: 17-22.

[21]. Yasinzai MI, Kakarsulemankhel JK. Alonso Pl, Brown G, Arevalo-Herrera M, Binka F, Chitnis C, Collins F, et al. A research agenda to underpin malaria eradication. PLoS Med 2011;8(1):e1000406.

[22]. Yasinzai MI, Kakarsulemankhel JK. Frequency of various human malaria infections in hottest areas of central Balochistan, Pakistan: Duki, Harnai and Sibi. Pak Armed Forces Med J 2008;58:276-85.

\section{Figures}

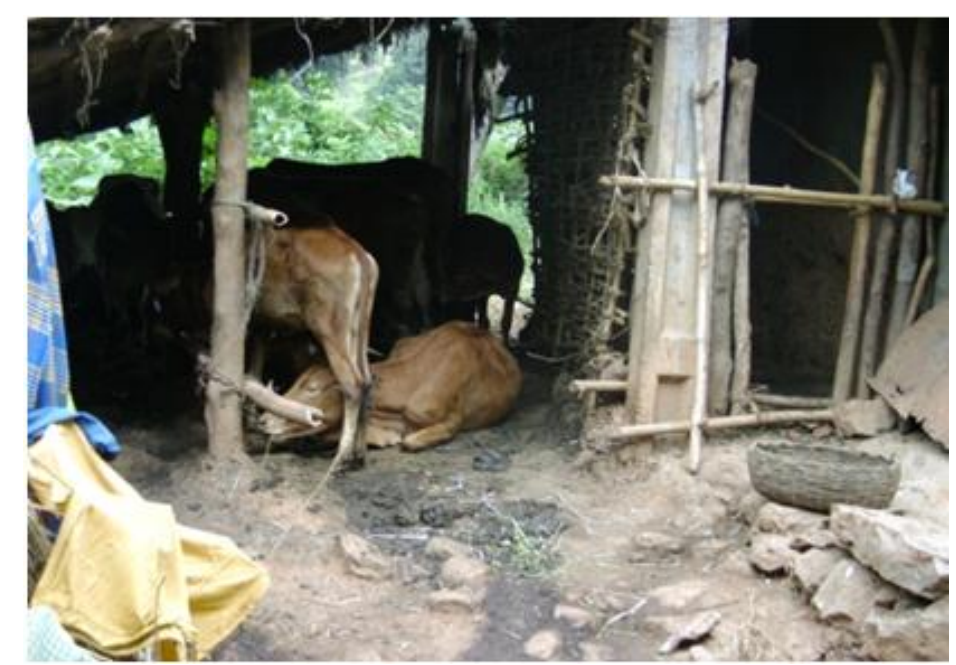

Fig. 1: A Cattle shed attached to house.

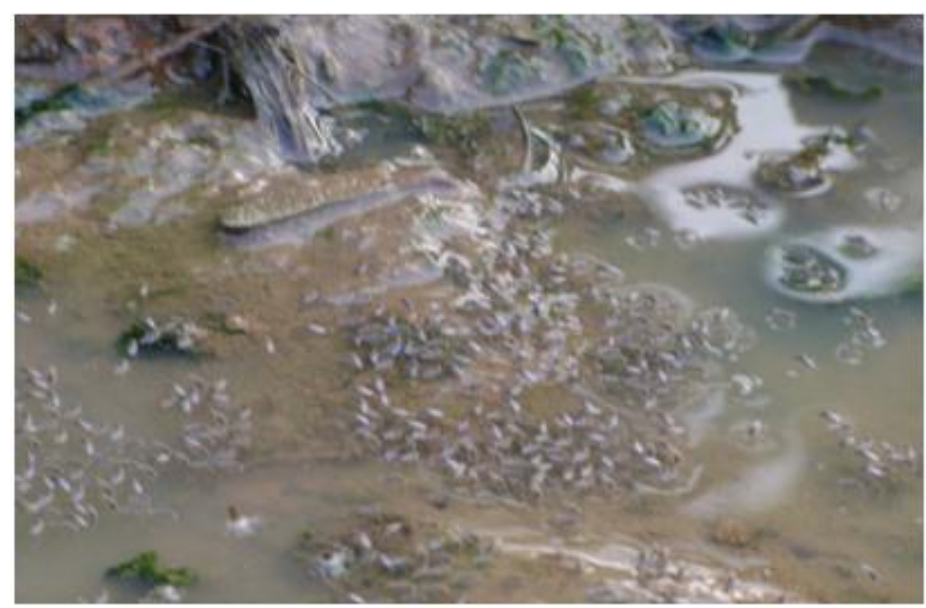

Fig. 2: Mosquitoes larvae and adults are in urinary pits of the cattle. 


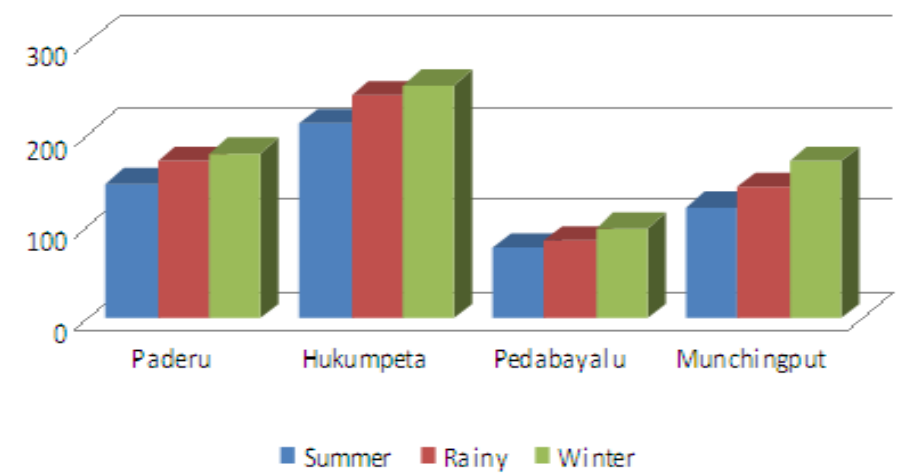

Fig. 3: Seasonal variation of Falciparum malaria in four mandals.

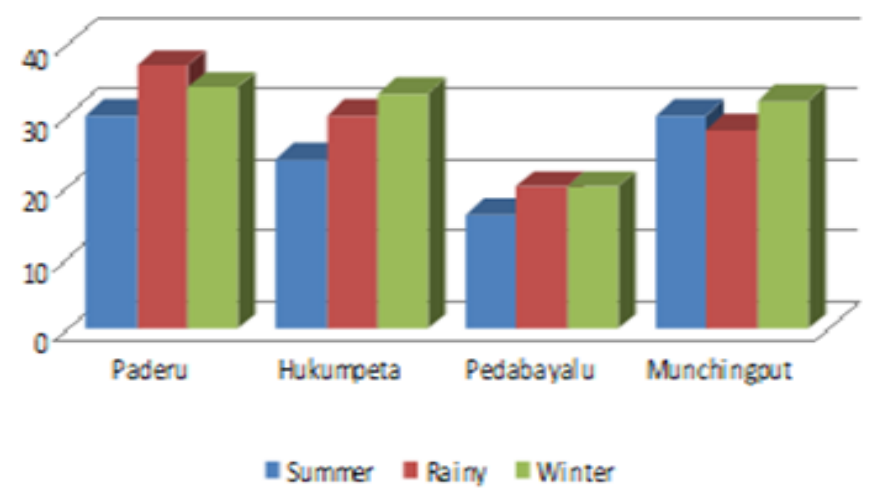

Fig. 4: Seasonal variation of Vivax malaria in four mandals.

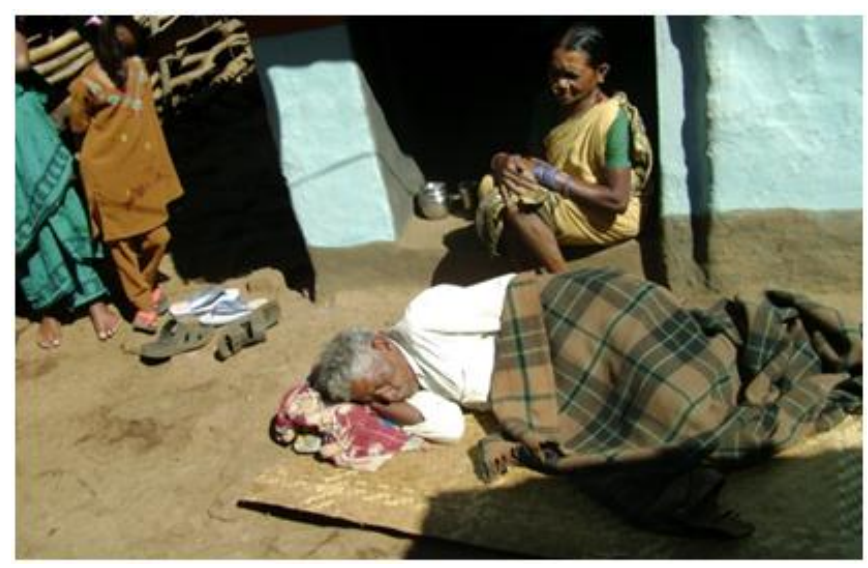

Fig 5: A Male patient suffering from malaria.

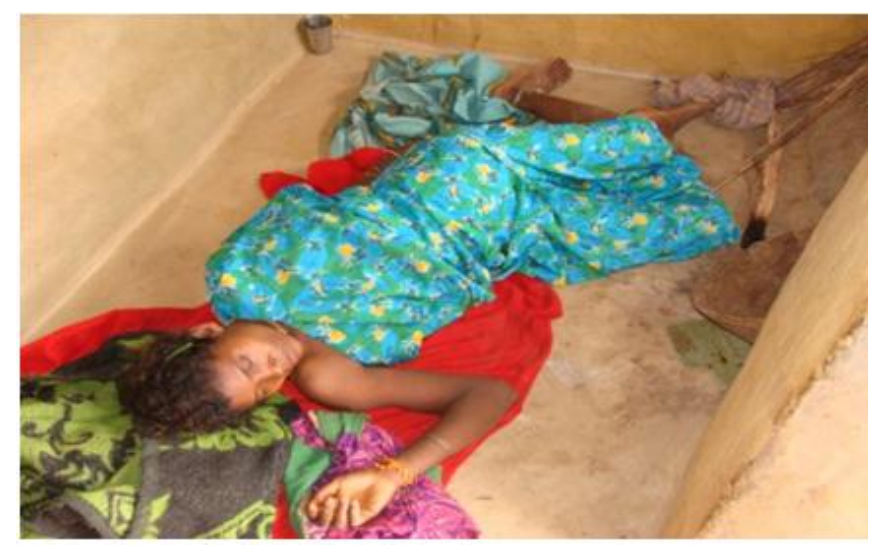

Fig 6: A Female patient suffering from malaria. 


\section{Tables}

Table 1: Mandal wise selected villages and sample size with population and patients particulars.

\begin{tabular}{lcccccc}
\hline Name of the Mandal & $\begin{array}{c}\text { Mandal } \\
\text { Population }\end{array}$ & $\begin{array}{c}\text { Total } \\
\text { Villages }\end{array}$ & $\begin{array}{c}\text { Studied } \\
\text { Villages }\end{array}$ & $\begin{array}{c}\text { Population of } \\
\text { Studied Villages }\end{array}$ & $\begin{array}{c}\text { Random } \\
\text { Sample size }\end{array}$ & $\begin{array}{c}\text { Total Patients } \\
\text { in 3 seasons }\end{array}$ \\
\hline Paderu & 53,329 & 200 & 94 & 22.659 & 5366 & 597 \\
Hukumpeta & 50,115 & 169 & 81 & 22.501 & 5361 & 793 \\
Pedabayalu & 50,831 & 272 & 56 & 14,355 & 3558 & 4671 \\
Munchingput & 43,918 & 310 & 96 & 17,419 & $\mathbf{1 8 9 5 6}$ \\
\hline Total & $\mathbf{1 9 8 1 9 3}$ & $\mathbf{9 5 1}$ & $\mathbf{3 2 7}$ & $\mathbf{7 6 9 3 4}$ & $\mathbf{2 2 2 6}$ \\
\hline
\end{tabular}

Table 2: Seasonal variation of malaria in tribals.

\begin{tabular}{|c|c|c|c|c|c|c|c|}
\hline \multirow{2}{*}{$\begin{array}{c}\text { Name of the } \\
\text { Mandal }\end{array}$} & \multirow[t]{2}{*}{ Specie of Parasite } & \multicolumn{6}{|c|}{ SEASONS } \\
\hline & & \multicolumn{2}{|c|}{ Summer } & \multicolumn{2}{|c|}{ Rainy } & \multicolumn{2}{|c|}{ Winter } \\
\hline \multirow{2}{*}{ Paderu } & Plasmodium falciparum & 146 & 0.64 & 170 & 0.75 & 180 & 0.79 \\
\hline & Plasmodium vivox & 30 & 0.16 & 37 & 0.16 & 34 & 0.15 \\
\hline \multirow{2}{*}{ Hukumpeta } & Plasmodium falciparum & 211 & 0.98 & 242 & 1.08 & 253 & 1.12 \\
\hline & Plasmodium vivox & 24 & 0.11 & 30 & 0.13 & 33 & 0.15 \\
\hline \multirow{2}{*}{ Pedabayalu } & Plasmodium falciparum & 76 & 0.53 & 84 & 0.59 & 98 & 0.68 \\
\hline & Plasmodium vivox & 16 & 0.11 & 20 & 0.14 & 20 & 0.14 \\
\hline \multirow{3}{*}{ Munchingput } & Plasmodium falciparum & 120 & 0.69 & 142 & 0.81 & 170 & 0.98 \\
\hline & Plasmodium vivox & 30 & 0.18 & 28 & 0.16 & 32 & 0.18 \\
\hline & & 653 & 3.29 & 753 & 3.82 & 820 & 4.22 \\
\hline
\end{tabular}

